\title{
A Japanese Utility Renewable Energy Management
}

\author{
Amin Mohammadirad, Sho Kainose, and Ken Nagasaka
}

\begin{abstract}
HOKKAIDO a northern island of Japan has high potentials of Solar and Wind energies. However, HOKKAIDO Electric Power Company (HEPCO) declares that by increasing Renewable Energy (RE) power such as Photovoltaic and Wind generation (hereafter PV and Wind), they cannot interconnect to the grid because of interconnection limitation and having surplus power in the grid. In this paper, for RE surplus power management, we suggest two solutions. The first solution is to convert RE surplus power to another type of energy which divided into two different methods. First, convert RE surplus power to $100 \%$ heat. Second, convert RE surplus power to $50 \%$ heat, $\mathbf{4 0 \%}$ hydrogen and $10 \%$ electric cars. For this purpose, we use the Advanced Energy System Analysis Computer tool called "EnergyPLAN" to estimate RE surplus power in HOKKAIDO future energy system. Then, we calculate and compare the conversation economic and environmental performances. The second solution is to transfer RE surplus power to connected multi-area networks. For this reason, we design load frequency control (LFC) in smart grid model of IEEE 30 bus test system in MATLAB/SIMULINK to give such ability to transfer power from one area to another. Finally, we compare both solutions economical and environment performances.
\end{abstract}

Index Terms-HOKKAIDO future energy system, surplus management, renewable energy (RE), conversion, transfer, multi-area networks, MATLAB/SIMULINK, smart grid.

\section{INTRODUCTION}

\section{A. Background Survey}

After World War II, the Japan's electric companies are divided in nine privately regional utilities such as HOKKAIDO, TOHOKU, HOKURIKU, TOKYO, CHUBU, SHIKOKU, KANSAI, CHUGOKU and KYUSHU electric power companies established in 1951 and after in 1972, OKINAWA electric power company became the tenth electric power company. The power demand and supply of all ten companies were about nearly $850 \mathrm{TWh} / \mathrm{Year}$ in 2013 which will increase to $980 \mathrm{TWh} /$ Year in 2030 [1]. The frequency of power grid is different in east and west of Japan, $50 \mathrm{~Hz}$ and $60 \mathrm{~Hz}$ respectively. TOHOKU (northeast of Japan) and KYUSHU (southwest of Japan) electric companies are connected together with backbone $500 \mathrm{kV}$ transmission line which gives the ability to such electric companies transfer power between each other. However, for different frequency in east and west such converters designed to transfer power (limited to $1 \mathrm{GW}$ ) between east and west. Since July 2012, the Japanese electric power companies agreed to purchase a huge

Manuscript received September 12, 2017; revised November 24, 2017.

The authors are with Department of Electronic and Information Engineering, Tokyo University of Agriculture and Technology, Tokyo, Japan (e-mail: amin.mohammadirad@gmail.com, kainosesho@gmail.com, bahman@cc.tuat.ac.jp). amount of RE such as PV, Wind, geothermal, etc; to fulfill the lack of generation supplied by terminated nuclear power plants.

The price which Japanese companies started to pay for $1 \mathrm{~kW}$ of power produced by PV was 42 yen before April 2013. However, and currently, the price for $1 \mathrm{~kW}$ is 28 yen [2].

This price is almost double of the electricity price which customers are paying now. It is quite natural that many companies rush to participate in the RE business but still there is some problems need to consider such as interconnection issues and RE surplus power management. One of the problems was stated by HEPCO, many investors and contractors are rushing to contract to sell their RE power. The contracts between consumers and Japanese electric companies, it is for 20 years and government forced the companies to purchase the RE from consumers in any conditions. However, HEPCO declares that they are able to purchase $1 / 4$ of the electricity because of interconnection limitation in their power grid.

The HOKKAIDO's RE potential is about $550 \mathrm{GW}$ which has the highest in whole Japan as shown in Fig. 1. As the results of Fig. 1, It is obvious that HOKKAIDO with such high potentials by increasing RE sources have surplus power problems in their energy system.

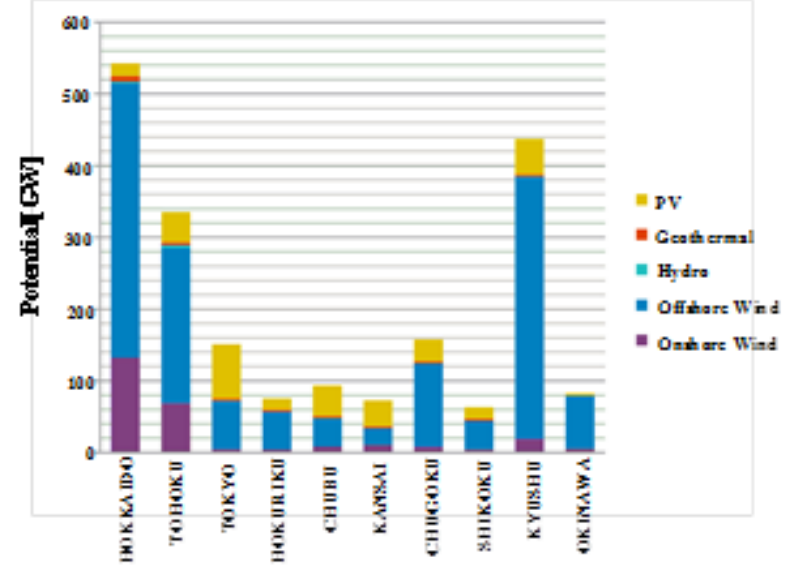

Fig. 1. Potential of RE (the Ministry of the Environment report and graph by Institute of Sustainable Energy Policies: ISEP) [3].

Recently, HEPCO announced that the possibility for interconnecting PV to the grid is limited to $1.17 \mathrm{GW}$ and for Wind only $0.36 \mathrm{GW}$ [4]. However, there are many projects ongoing for Mega-solar or Wind farm in the present which the total amount of certified and operation of RE is higher than the interconnection limitation and need to be considered seriously. This problem is not only limited to HEPCO but also happen in other power companies in entire Japan. The Fig. 2 and 3 sourced by Ministry of Economic, Trade, and Industry (METI) show the PV certified, PV operation, PV allowable to connection amounts, Wind certified, Wind operation and Wind allowable to connection amounts 
respectively. Also, according to Japan's energy plan (energy mix) report [5], in 2030 the nation's RE will increase about 20-24\% which HOKKAIDO will definitely be participating of RE market and play a big role in Japan's electricity market. Therefore, interconnection limitation will bring many difficulties for investors and electric companies and should be considered very seriously on how to manage RE surplus power in their energy system. There are many techniques and technologies to manage such as saving in batteries [6] but it is costly and has short lifetime storage.

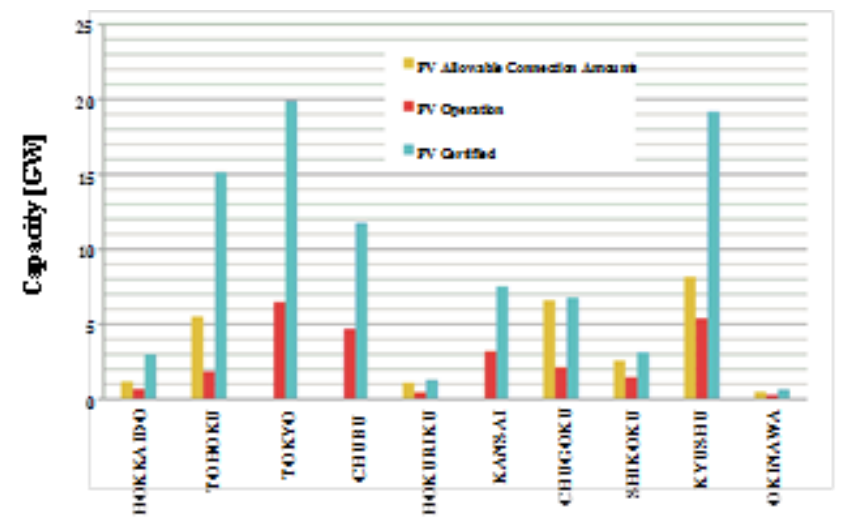

Fig. 2. PV allowable connection amounts, PV operation, and PV certified capacity of total utilities of Japan graph by Institute of Sustainable Energy Policies (ISEP) [7]



Fig. 3. Wind allowable connection amounts, wind operation and wind certified capacity of total utilities of Japan graph by Institute of Sustainable Energy Policies (ISEP) [7].

Recently, there is another way to store power which is convert electrical energy to another type of energy such as heat, hydrogen or electric cars usage for transportation which is considered in this paper as the first solution. For this purpose, we used the Advanced Energy System Analysis Computer tool EnergyPLAN. "The tool is included national and regional energy systems, which includes heat and electricity supplies as we as the transport and industrial sectors. All Thermal, Renewable, storage conversion, and transportation technologies can be modeled by EnergyPLAN [8] which is unique in comparison with many other tools [9]. The tool is deterministic input/output tool and general inputs are demands, RE sources, energy technology capacities, costs and a number of option regulation strategies for import/export and excess electricity production, all on an hourly basis. The tool is also able to include analyses combining fluctuating RE sources with the production of synthetic gases or liquids in addition to the capacity to include different types of biofuels. The analyses in
EnergyPLAN is supplemented by GIS (Geographical Information Systems) based mapping and analysis of heat demand and supply options by means of spatial analysis using highly detailed heat atlases of the building stock by age, use and current heat supply, the economically accessible potentials of energy efficiency, the expansion of energy infrastructure, as well as the locally available RE sources are identified by means of cost-supply curves" [10], [11]. The second solution is transferring RE surplus power to connected multi-area networks. For this reason, first, we decompose the smart grid model of IEEE 30 bus test system into three different areas; area 1, area 2 and area 3 . Each area is a role as one electric power company. Then, we designed LFC system in MATLAB/SIMULINK and applied on this model to give such ability to transferring power between each area.

\section{B. HOKKAIDO Energy in Future (The year 2030)}

The Japan's energy plan (energy mix) for 2030 which estimated by Japan's Ministry of Economic, Trade, and Industry(METI) [5] will change to nuclear power(20-22\%), thermal power (27\% Liquid Natural Gas(LNG), 26\% coal, $3 \%$ oil) and RE (20-22\%). The total electricity demand estimated by METI is about 1065TWh per year. However, they are another sources [1] which estimated total electricity demand will increase about $980 \mathrm{TWh} /$ Year. Also, according to Japan's National Institute of Population and Social Security Research [12], Japan facing population declines. The Japan population in present is about 127 million but will decrease to 117 Million in 2030 which will effect on electricity demand. For this reason, our calculation for electricity demand in future is based on 980TWh/Year. The comparison of Japan's energy mix in present and future is shown in Fig. 4.



Fig. 4. Japan's energy mix comparison in present and future.

As results of Fig. 4, nuclear power will increase from $1.1 \%$ to $22 \%$. Also, the oil decrease from $9 \%$ to only $3 \%$. For this reason, Japan's energy mix in future, the cost will reduce because increasing nuclear power and more $\mathrm{CO} 2$ emission will decrease because of increasing RE generation. The RE which will increase about $22-24 \%$ in future including $7 \% \mathrm{PV}$, $1.7 \%$ Wind, $3.7-4.6 \%$ biomass, $1.0-1.1 \%$ geothermal and 8.8-9.2\% hydro as shown in Fig. 5.

In this study, we used all estimated information about Japan's energy mix to calculate HOKKAIDO energy system in future. HEPCO share about $4 \%$ electricity of Japan. For this reason, the HOKKAIDO electricity demand in future is about $39 \mathrm{TWh} /$ Year. There is no exact information about HOKKAIDO heat demand in future. However, HOKKAIDO 
Bureau of Economic, Trade, and Industry published reports [13] about HOKKAIDO energy balance in 2013. As the results of the report, heat demand estimated approximately about $10 \mathrm{TWh} /$ Year in 2010. However, in the case of increasing heat demand during this year from 2010, we estimated heat demand about $20 \mathrm{TWh} / Y$ ear. We estimate heat supply according to the HOKKAIDO Heat Supply Authority (HHSA) [14]. The HHSA introduced exist energy centers in HOKKAIDO area. There are six stations in HOKKAIDO which one station produced only heat by fuel boiler (30\% natural gas, 69\% coal, 1\% biomass) between years 2005 to 2007 . However, the energy center decreases the coal to $0 \%$ and use natural gas in the share of about $78 \%$ and about $22 \%$ biomass for $\mathrm{CO} 2$ emission. Another five stations, according to their system flow they are able to cogenerate the electricity and heat.

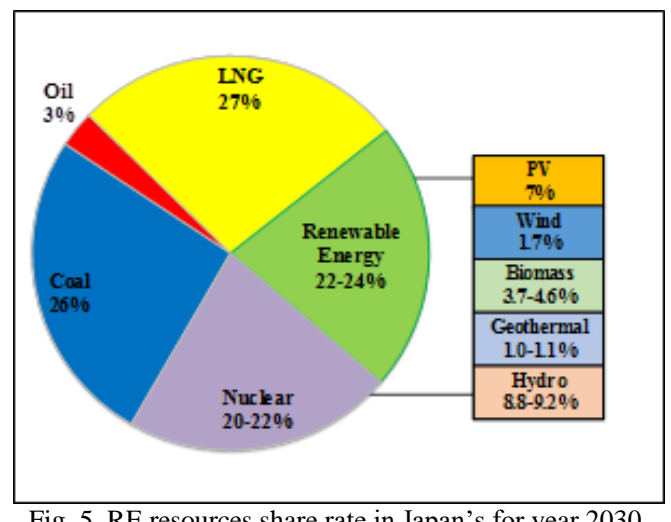

The RE in HOKKAIDO energy system in future will increase to about $9.4 \mathrm{TWh} /$ Year. The hydropower amount will increase to $8.8-9.2 \%$ which already hydropower share $10-15 \%$ of the total electricity of Japan. The combined heat and power (CHP) can generate heat and electricity, in $30-60 \%$ and $20-45 \%$ respectively. In HOKKAIDO present situation $15 \%$ of electricity supplied by CHP and $85 \%$ by thermal power plants (hereafter PP). However, CHP in comparison of thermal power plants have more energy efficiency up to $70-90 \%$ but thermal energy efficiency is about $40-45 \%$ and making more $\mathrm{CO} 2$ [15]. For this reason, for optimal operation, we designed CHP system to be about $20 \%$ electricity and $80 \%$ heat supply for HOKKAIDO energy in future. The PP supplied $64 \%$ of electricity is present. However, replacement of nuclear power and CHP, the PP only share $36 \%$ of total electricity in HOKKAIDO future energy system which decreasing more $\mathrm{CO} 2$ from 16.79 Million ton to 15.26 Million ton.

\section{TeChniQues AND Simulation}

\section{A. Conversion of RE Surplus Power}

HOKKAIDO energy system in future designed in EnergyPLAN and shown in Fig. 6. In Fig. 6, HOKKAIDO future energy system includes 57\% PP and CHP, 24\% RE and $20 \%$ nuclear power for electricity. For heat demand, by increasing CHP generation for electricity, CHP share $62 \%$ of heat and fuel boiler share $37 \%$ of total heat demand. In Fig. 6 , $\mathrm{PP}$ amount is the sum of nuclear, thermal and hydro power plants. Also, we designed 50GWh/14days heat storage for balancing heat and electricity in the future energy system. In addition, EnergyPLAN for balancing electricity demand and optimization of energy system as an environmental factor, by increasing the amount of RE, thermal power amount reduced. However, by increasing RE and decreasing thermal power still, we have RE surplus power in our energy system which is about $0.66 \mathrm{TWh} /$ Year. Therefore, we used two different methods for RE surplus power management. First, we convert all surplus power to only heat (100\% heat). Second, we convert RE surplus power to $50 \%$ heat, $40 \% \mathrm{H}_{2}$ and electric cars usage. The reason we used these two different methods is to compare both conversion tools economically and environmentally. For this reason, we calculate and compare the economy and environment performances of each conversion tools for HOKKAIDO future situation. For calculating cost we used EneryPLAN cost database. "The EnergyPLAN cost database is created and maintained by the Sustainable Energy Planning Research Group at Aalborg University, Denmark. The cost database and the result is a collection of investment costs, operation \& maintenance costs, fuel costs and lifetimes for all technologies for the years 2020, 2030, and 2050" [16]. We used 2030 costs information and applied to HOKKAIDO future energy system.

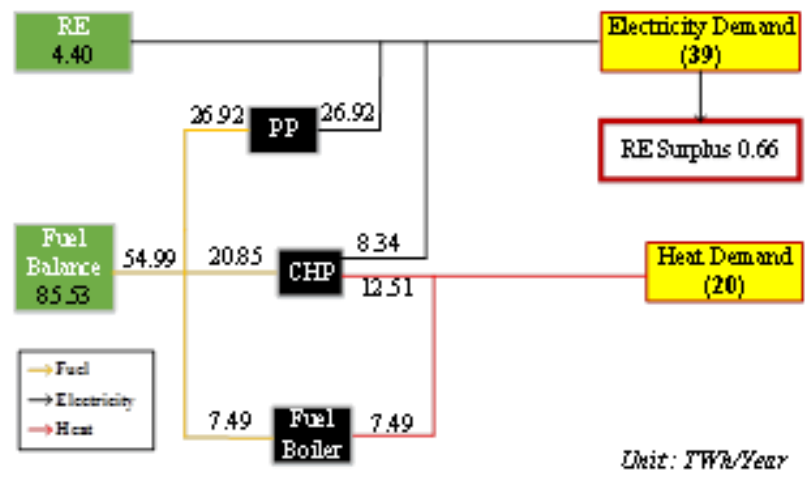

Fig. 6. HOKKAIDO future energy system (2030).

\section{B. Convert RE Surplus to $100 \%$ Heat}

We convert total RE surplus power to heat (100\%) heat conversion) by using $255 \mathrm{MW}$ capacity heat pumps. Also, for balancing heat demand we increased the amount of heat storage from $50 \mathrm{GWh} / 14$ days to $150 \mathrm{GWh} / 14$ days. The HOKKAIDO future energy system with $100 \%$ heat conversion is designed in EnergyPLAN and is shown in Fig 7.

Also, the cost and environment performances of Fig. 7 is calculated and shown in Table I. In Fig. 7, by adding heat pumps to the energy system, we are able to produce $32 \%$ of our total heat from RE surplus power. Therefore, RE amount dropped from 4.40 TWh/Year to 4.02 TWh/Year. The total $\mathrm{CO} 2$ emission of total HOKKAIDO future energy system is 15.26 Million ton per year. However, this amount of add heat pumps to convert RE surplus to heat, dropped to 14.08 Million ton.

C. Converting RE Surplus to 50\% Heat, $40 \% \mathrm{H} 2$ and Electric Cars 
We convert RE surplus power in the share of $50 \%$ heat, $40 \%$ use Electrolyser to produced hydrogen $\left(\mathrm{H}_{2}\right)$ and $10 \%$ electric cars. The model designed and shown in Fig. 8. Also, the cost and environment performances of Fig. 8 is calculated and shown in Table II. In Fig. 8, the heat pumps capacity decreased from $255 \mathrm{MW}$ to $34 \mathrm{MW}$ and only share of $12 \%$ of heat demand. Also, heat storage decreased from 155 $\mathrm{GWh} / 14$ days to $20 \mathrm{GWh} / 14$ days for balancing the heat demand.

The fuel boiler share increased from $7 \%$ to $25 \%$ share of total heat demand because of decreasing amount of heat pumps. As results Table II, The amount of $\mathrm{CO}_{2}$ emission increased to 15.34 Million ton per year in comparison to Table I results. The electric cars investment costs calculated based on $10 \mathrm{kWh} / 100 \mathrm{Km}$. Electric cars for runs $100 \mathrm{Km}$ need about $10 \mathrm{kWh}$ electricity power. Annually electric cars run about $24,000 \mathrm{Km} /$ Year [17]. The conversion amount of RE surplus power for electric cars usage is about $10 \%$ which is about $66 \mathrm{GWh} /$ Year. This amount able to runs about 28,000 cars per year which total cost calculated in Table II.

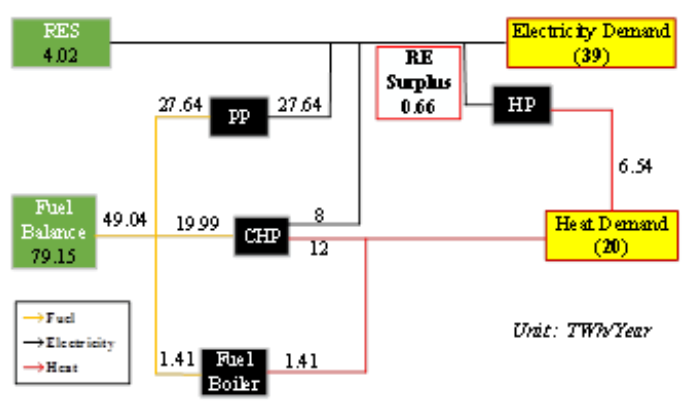

Fig. 7. RE surplus power converting to $100 \%$ heat by heat pumps.

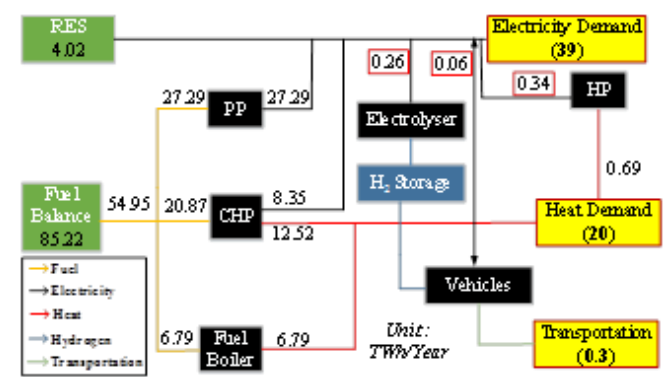

Fig. 8. RE surplus power converting to $50 \%$ heat, $40 \% \mathrm{H}_{2}$ and $10 \%$ electric cars.

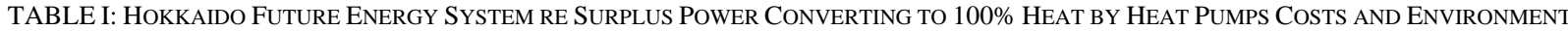
PERFORMANCES

\begin{tabular}{|c|c|c|c|c|c|c|}
\hline \\
\hline & & \multirow[b]{2}{*}{$\begin{array}{l}\text { Installed } \\
\text { Capacity }\end{array}$} & \multirow[b]{2}{*}{$\begin{array}{l}\text { Total Investment Cost } \\
{\left[10^{8} \mathrm{JPY}\right]}\end{array}$} & \multicolumn{2}{|c|}{ Annual Cost $\left[10^{9} \mathrm{JPY}\right]$} & \multirow[t]{2}{*}{ Total $\mathrm{CO}_{2}$ Emission $\left[10^{6}-\mathrm{Ton}\right]$} \\
\hline & & & & Fixed Cost & FixedO\&M & \\
\hline \multirow{2}{*}{ Genration } & Wind & $348[\mathrm{MW}]$ & 348 & 20 & 9 & \multirow{4}{*}{14.08} \\
\hline & $P V$ & $1535[\mathrm{MW}]$ & 1259 & 54 & 13 & \\
\hline Conversion & Heat Pump & $255[\mathrm{MW}]$ & 875 & 50 & 17 & \\
\hline Storage & Heat Storage & $\begin{array}{c}150 \text { [GWh] } \\
\text { (For 14 Days) }\end{array}$ & 450 & 30 & 3 & \\
\hline
\end{tabular}

TABLE II: HOKKAIDO FutuRE ENERGY SYSTEM RE SURPLUS POWER CONVERTING TO 50\% HEAT, 40\% H2, $10 \%$ ELECTRIC CARS COSTS AND ENVIRONMENT PERFORMANCE

\begin{tabular}{|c|c|c|c|c|c|c|}
\hline & & \multicolumn{2}{|r|}{ PERFORMANCE } & \multicolumn{2}{|c|}{ Annual Cost $\left[10^{9} \mathrm{JPY}\right]$} & \multirow{2}{*}{$\begin{array}{l}\text { Total } \mathrm{CO}_{2} \\
\text { Emission }\left[10^{6}\right. \\
\text { Ton] }\end{array}$} \\
\hline & & Installed Capacity & $\begin{array}{l}\text { Total Investment Cost } \\
{\left[10^{8} \mathrm{JPY}\right]}\end{array}$ & Fixed Cost & Fixed O\&M & \\
\hline \multirow{2}{*}{ Genration } & Wind & $348[\mathrm{MW}]$ & 348 & 20 & 9 & \multirow{7}{*}{15.34} \\
\hline & $P V$ & 1535 [MW] & 1259 & 54 & 13 & \\
\hline \multirow[b]{3}{*}{ Conversion } & Heat Pump & $134[\mathrm{MW}]$ & 134 & 8 & 3 & \\
\hline & Electrolyser & $160[\mathrm{MW}]$ & 56 & 5 & 2 & \\
\hline & Electric Cars & $\begin{array}{c}66[\mathbf{G W}] \\
(28000 \text { cars })\end{array}$ & 507 & 40 & 22 & \\
\hline \multirow[t]{2}{*}{ Storage } & Heat Storage & $\begin{array}{c}20 \text { [GWh] } \\
\text { (for } 14 \text { Days) }\end{array}$ & 60 & 7 & 0 & \\
\hline & Hydrogen Sorage & 350 [GWh] & 7000 & 871 & 35 & \\
\hline
\end{tabular}

Finally, we compare two different methods of conversation as the economy and environmental performance. The results are shown in Table III.

TABLE III: LOOK-UP-TABLE OF COMPARISON ECONOMY AND Economy $\stackrel{\text { ENVIRONMENT PERFORMANCES OF CONVERSION TOOLS }}{\longrightarrow}$ Environment

\begin{tabular}{|c|c|c|}
\hline Conversion Method & $\begin{array}{c}\text { Total Investment } \\
\text { Cost } \\
{\left[\mathbf{1 0}^{8} \mathbf{J P Y}\right]}\end{array}$ & $\begin{array}{c}\text { Total } \mathrm{CO}_{2} \text { Emission } \\
{\left[\mathbf{1 0}^{\mathbf{6}} \text { Ton] }\right.}\end{array}$ \\
\hline $\mathbf{1 0 0 \% ~ H e a t}$ & 875 & 14.08 \\
\hline $\begin{array}{c}\mathbf{5 0 \%} \text { Heat, 40\% } \mathrm{H}_{2}, \\
\mathbf{1 0 \%} \text { Electric cars }\end{array}$ & 697 & 15.34 \\
\hline
\end{tabular}

\section{Transfer to Connected Multi-area Networks}

Regarding RE surplus power transfer to other networks, as a complete and detail information of entire Japanese electric power companies is not available, here in this study, the IEEE 30 bus test model system is considered as shown in Fig. 9. By using this model system we can do all necessary simulations. In the IEEE 30 bus test model system, first, we decompose the entire model into 3 areas which are connected by tie lines. Then, we try to transfer the RE surplus power from HEPCO (area 1) network to multi-area networks as shown in Fig. 10.

E. Smart Grid Model of IEEE 30 Bus Test System Multi-area Networks 
In this paper, the second solution for RE surplus management is transferred it to connected multi-area networks. For this reason, we used smart grids model of IEEE 30 bus test system on the MATLAB/Simulink which is designed for the first time at the Environmental Energy Laboratory of Tokyo University of Agriculture and Technology [18]. Previously, many power system models including small and large-scale smart grids were designed at the Environmental Energy Laboratory of Tokyo University of Agriculture and Technology. Since 2009, they have started to design small-scale and large-scale smart grids simulation model on the MATLAB/Simulink [19], [20]. For lack of place sake, only a brief introduction of their large-scale smart grid system is presented. This model incorporates the communication blocks into the IEEE 30 bus power system, all designed on the MATLAB/Simulink [21].
Their communication model can reproduce influence which usually occurs in communication, such as noise, delay, fluctuation of the arrival time of packets, and packet loss. In model construction, effective design is given to prevent a drop in simulation speed. In another case study on the smart grid [22]. As this is a large-scale model, it is required that both power system and communication blocks work efficiently. Based on their simulations, they have verified the performances of their smart grid model. It works properly and smoothly as expected [20]-[23]. The model designed in MATLAB/Simulink and shown in Fig. 9. Therefore, for transferring RE surplus power to connected multi-area networks we designed LFC to give the ability to the model to transfer power between each area. The construction of communication of this model in details explained very well in previous [21], [22].

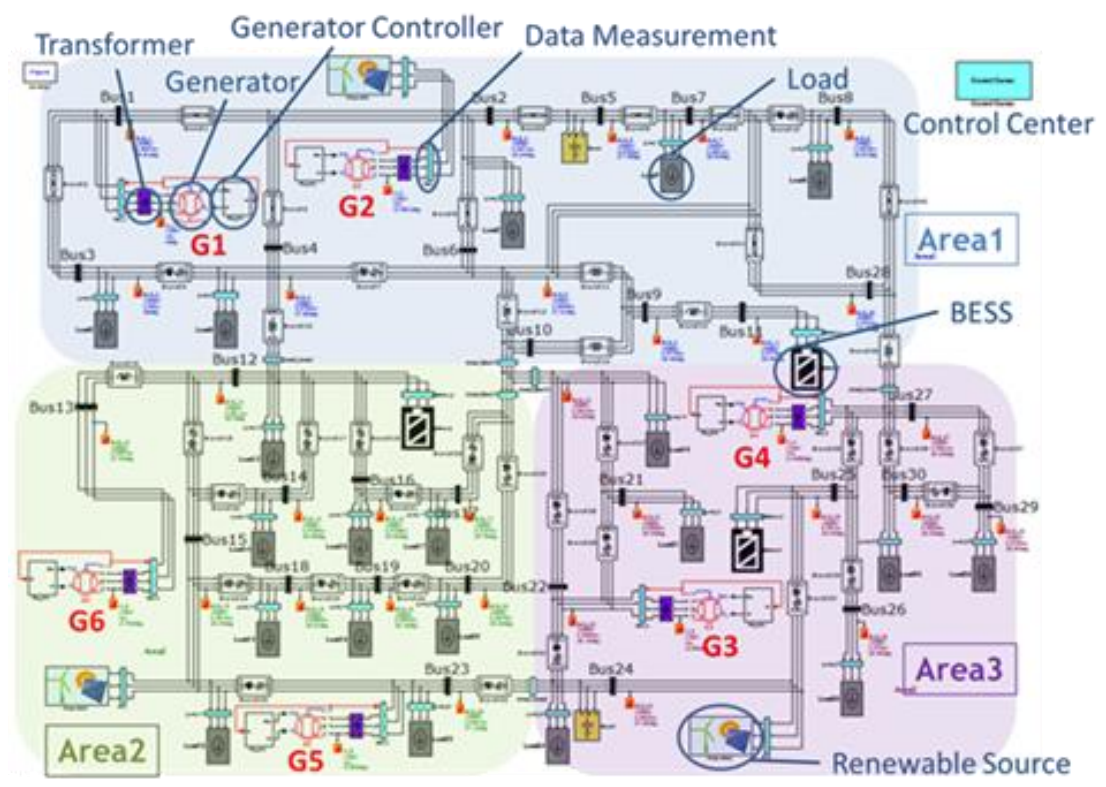

Fig. 9. IEEE 30 bus smart grid total.

\section{F. Transmission Transferability}

In this paper, we consider on area 1 which have RE surplus power and need to transfer it to connected multi-area networks. area 1 have $600 \mathrm{MW}$ limited transmission line capacity (will be increased to 900 MW by 2019 [24]). In addition, the transferring power between utilities is not only in an emergency (imbalance situation) and Japanese electric companies have a contract to purchase power from each other yearly. There is report [25] which published by Organization for Cross-regional Coordination of Transmission Operators (OCCTO) in Japan. This report shows the transfer capacity from area 1 is limited to 5\% 10\% of total power. However, another area transfer capacity is unlimited as shown in Fig. 10.

The LFC system designed in this model to transfer power from one area to another. Each area is connected to $6 \mathrm{MW} \mathrm{PV}$ and includes two generators which total amount of generators and PV as supply are equal and balanced with demand. The simple diagram of LFC system between each area in case of no transferring power situation is shown in Fig. 11.

Since supply and demand of each area are a balance, the LFC System between areas will be zero. We increased $6 \mathrm{MW}$
PV in area 1 and area 2 to $16 \mathrm{MW}$ which shown in Fig. 12 and Fig. 13. Since, PV amount increase to $16 \mathrm{MW}$, it is obvious that total supply in area 1 and area 2 increased (about $10 \mathrm{MW}$ ) and supply and demand become imbalanced as shown Fig. 14 and Fig. 15. This mean area 1 and area 2 have RE surplus power. At the same time, we decreased $20 \mathrm{MW}$ from generator 3 in area 3 . Then, area 3 to fulfill the lack of supply need to purchase power immediately from another area as shown in Fig. 16.



Fig. 10. Transfer capacity from HOKKAIDO to multi-area networks. 


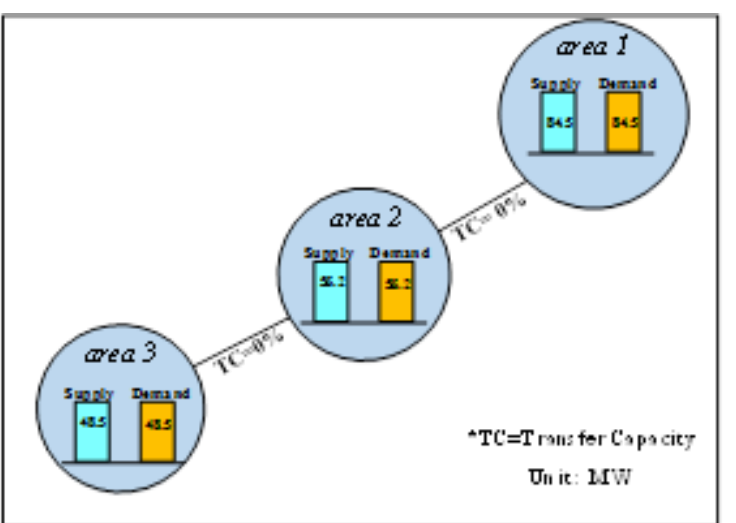

Fig. 11. The simple diagram of balanced multi-area with LFC control.

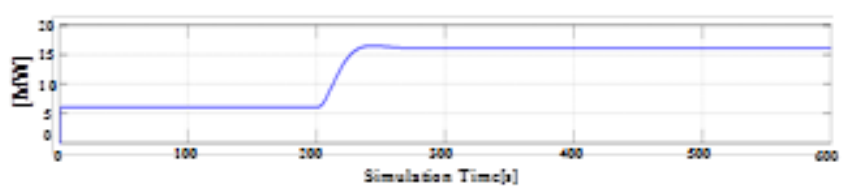

Fig. 12. Connected-PV amount increased from $6 \mathrm{MW}$ to $16 \mathrm{MW}$ in area 1.

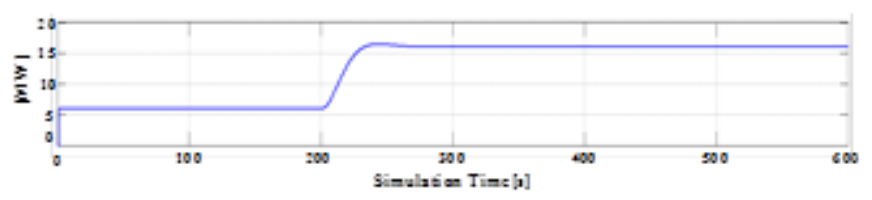

Fig. 13. Connected-PV amount increased from $6 \mathrm{MW}$ to $16 \mathrm{MW}$ in area 2.

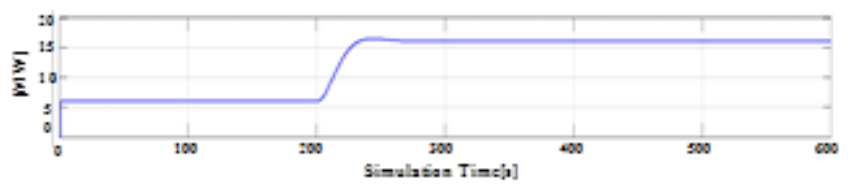

Fig. 14. Total generation increased cause of PV amount increased from 6 MW to $16 \mathrm{MW}$ in area 1.



Fig. 15. Total generation increased cause of PV amount increased from 6 MW to $16 \mathrm{MW}$ in area 2.

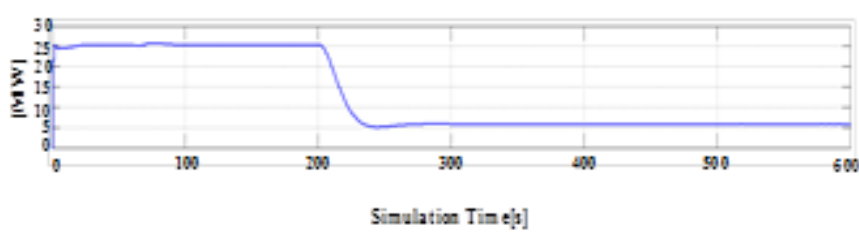

Fig. 16. $20 \mathrm{MW}$ generation drop in area 3.

In Fig. 12 and Fig. 13, by increasing PV amount, we have RE surplus power in area 1 and area 2 and lack of supply in area 3. Therefore, the LFC system starts to transfer the RE surplus power in area 1 and 2 (about $20 \mathrm{MW}$ ) to area 3 to fulfill the lack of supply in area 3 and balance the supply and demand. The LFC results are shown in Fig. 17, Fig. 18 and Fig. 19.

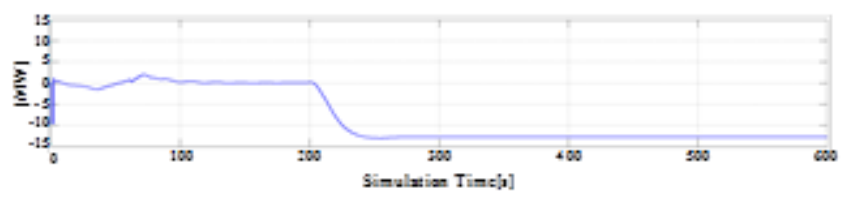

Fig. 17. RE surplus power transfer from area 1 to area 2.

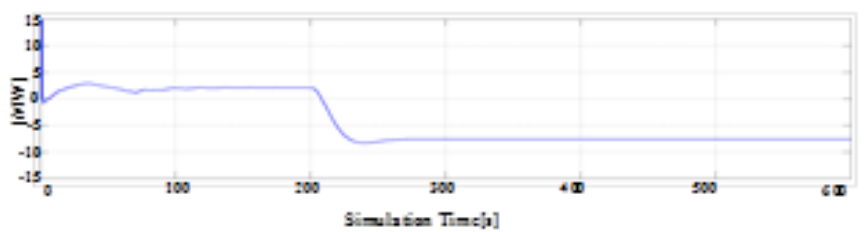

Fig. 18. RE surplus power transfer from area 2 area 3.

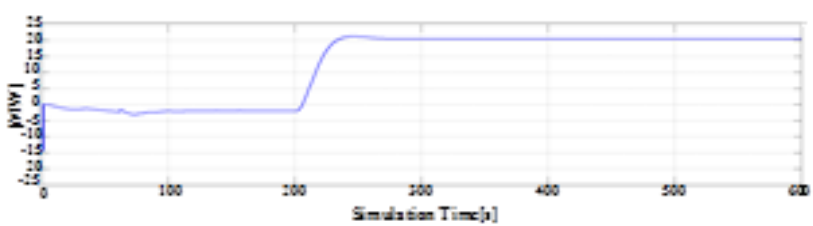

Fig. 19. Total RE surplus power transfer from areas 1 and 2 entered area 3.

The LFC system (-) value, it means power send out from the area and (+) value the power entered the area. As the results of the simulation, the area 1 and area 2 transferred RE surplus power according to the transfer capacity (about 10 MW from each area) to fulfill the lack of generation. The total power which transferred from area 1 and 2 to area 3 by LFC system is about $+20 \mathrm{MW}$. The simple diagram of transferred power between each area is shown in Fig. 20.

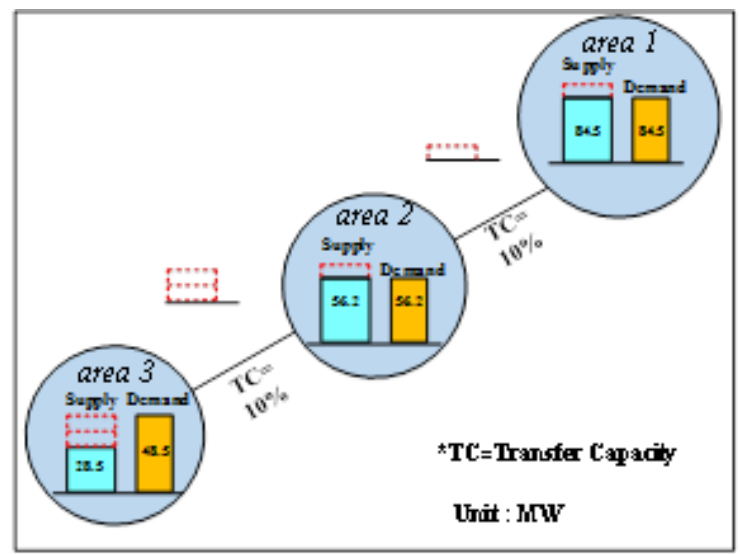

Fig. 20. The simple diagram of transferring power from area 1 to area 3 via area 2 with LFC system.

\section{RESUltS AND DisCUSSIONS}

In this study, we used two different solutions for RE surplus power management. The first solution is converting RE surplus power to another type of energy. Second, transferring RE surplus power to connected multi-area networks. As result of conversion method, as economy factor converting RE surplus power to more than one type of energy such as $50 \%$ heat, $40 \%$ hydrogen and $10 \%$ electric cars, it is cheaper than convert all to heat. As results of transferring RE surplus power to connected multi-area networks area 1, transferring is limited. The total RE surplus power in future which calculated in the previous section is about 0.66 TWh/Year. According to both converting and transferring solution results, HEPCO for RE surplus power management is able to transfer power to connected multi-area networks limited to $10 \%$ and rest about $90 \%$ conversions. Finally, the scheme of HOKKAIDO RE surplus power management considering on conversion and transferring solution is shown in Fig. 21. Therefore, we calculate the transferring and conversions cost as shown in Table IV. For transferring costs, a reports [26] is used which declared the electricity price 
which purchased by electric power company from another about $13 \mathrm{JPY} / \mathrm{kWh}$ in an average of three years (from 2013 to 2015).

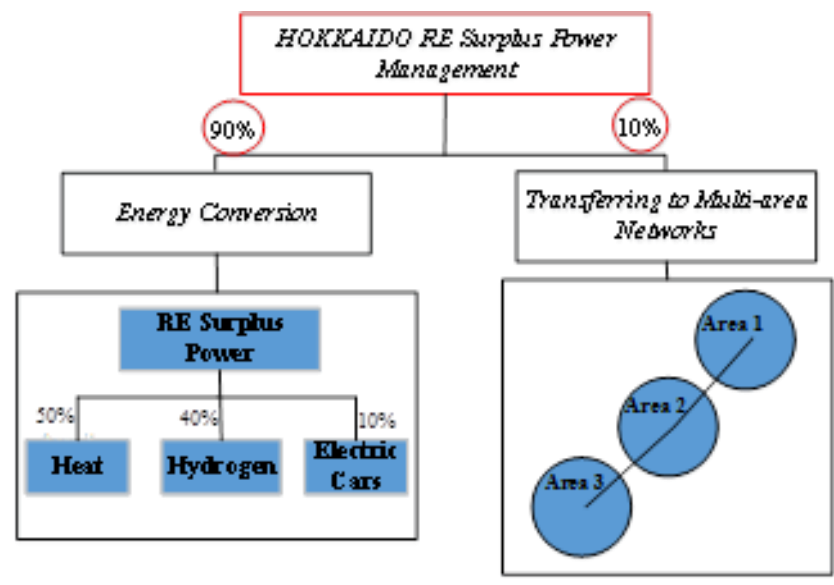

Fig. 21. The scheme of HOKKAIDO RE surplus power management considering on conversion and transfer.

TABLE IV: HOKKAIDO RE SURPLUS POWER MANAGEMENT COST CONSIDERING CONVERSION AND TRANSFER

\begin{tabular}{|c|c|c|c|}
\hline $\begin{array}{c}\text { Management } \\
\text { Method }\end{array}$ & {$[\%]$} & $\begin{array}{c}\text { Amount of Surplus } \\
\text { [TWh/Year] }\end{array}$ & $\begin{array}{c}\text { Total } \\
\text { Cost } \\
{\left[1^{8} \mathbf{J P Y}\right]}\end{array}$ \\
\hline Conversion & 90 & 0.59 & 83 \\
\hline Transfer & 10 & 0.066 & 0.9 \\
\hline
\end{tabular}

As the result of Table IV, transferring RE surplus power to multi-area networks is cheaper than conversions. Therefore, by increasing area 1 -area 2 transmission capacity, area 1 have more flexibility on transferring RE surplus power to Multi-area networks. However, as we mentioned before transferring power between electric companies in Japan is somehow is limited and also Japanese electric companies need to consider on conversion solution seriously.

\section{CONCLUSION}

HOKKAIDO future energy system analyzed and designed in EnergyPLAN. The amount of surplus power which accomplished by increasing RE calculated. Then, as the first solution, we calculated the cost and environment performance of two different conversion tools for RE surplus management. The first method was converting all RE surplus power to $100 \%$ heat. Second, convert it to $50 \%$ heat, $40 \%$ Hydrogen and $10 \%$ electric cars. Next, we made a look-up table and compare both methods economically and environmentally to find optimal conversation method. The second solution for RE surplus power management is transferring it to connected multi-area networks. For this reason, we designed LFC system to give such ability to transfer power (about 10\%) between each area in smart grid model of IEEE 30 bus test system. HEPCO and other utilities which have RE surplus power in their energy system forced the government legislation to give them rights to stop purchasing total RE from consumers (contractors). However, this action may bring difficulties for consumers and it is dishonesty on their contract between companies and consumers. The authors believe that the above solution is not good and enough for solving interconnection limitation. For this reason, we believe that this study may help them to consider on existing solutions such convert or transfer RE surplus power. Also, this study helps them to choose the optimal conversion tools which are a match for their energy system and optimized by two important factors cost and environment performances. Finally, we believe that this study is not limited to Japan. Other countries facing surplus power in their energy system cause of increasing RE sources in near future may benefit from our proposed method.

\section{REFERENCES}

[1] The Federation of Electric Companies of Japan Report, "Electricity review of Japan," 2016.

[2] L. Plessis, Energy\&Enviroment Specialist in Japan External Trade Organization (JETRO) in London “Japan's Solar PV Market Overview, November 2015.

[3] Institue of Sustainable Energy Policies (ISEP), "Renewables 2015 Japan status report," October 2015.

[4] The HOKKAIDO Electric Company Report, "Connectable amount of Renewable energy (calculated in FY 2016)," November 2016.

[5] The Ministry of Economic, Trade, and Industry of Japan (METI), “Japan's energy plan,” 2017.

[6] H.-R. Zhao and Q.-W. Wu, "Review of energy storage system for wind power integration support," Journal of Applied Energy, Elsevier, vol. 137, pp. 545-553, January 2015.

[7] Institue of Sustainable Energy Policies (ISEP) Report, "Renewables 2016 Japan Statues," October 2016.

[8] L. Henrik, EnergyPLAN-Advanced Energy System Analysis Computer Model. Documentation Version 11.01.14.

[9] C. David, Finding and Inputting Data into EnergyPLAN. Aalborg, Denmark: Aalborg University, 2015.

[10] B. Moller, "A heat atlas for demand and supply management in Denmark," Manage Environ Qual 2008, vol. 19, pp. 467-79.

[11] B. V. Mathiesen, H. Lund, and D. Connoly, "Smart energy systems for coherent $100 \%$ renewable energy and trasport solutions," Journal of Applied Energy, vol. 145, pp. 139-154, May 2015.

[12] The Agency of Natural Resources and Energy, "Energy demand forcast report," April 2015.

[13] Ministry of Economic, Trade, and Industry (METI) HOKKAIDO Bureau of Economy report," HOKKAIDO energy consumption viewed on a graph," 2016.

[14] HOKKAIDO Heat Supply Authority website. [Online]. Available: http://www.hokunetsu.co.jp/jigyousyo.html

[15] HOKKAIDO Gas Company (KITAGAS) website, "Gas cogeneration reduced energy consumption," 2017.

[16] The Sustainable Energy Planning and Management Research Group, "EnergyPLAN cost database," January 2015.

[17] Department of Energy (DOE), Transportation Energy Data Book, 2015.

[18] Environmental Energy Engineering Laboratory. [Online]. Available: http://www.tuat.ac.jp/ bahman/

[19] Y. Hayashi, "Geographical information system used for design and evaluation of grid inter-connected off-shore wind power," Master's thesis of Tokyo University of Agriculture and Technology, 2013.

[20] Y. Ueno, "Renewable energy generation penetration limits in distribution systems," Master's thesis of Tokyo University of Agriculture and Technology, 2014.

[21] S. Kainose and K. Nagasaka, "A research on construction of IEEE 30 bus large-scale smart grid model," in Proc. the 2015 International Conference on Advanced Mechatronic Systems, Beijing, China, August 22-24, 2015.

[22] S. Kainose and K. Nagasaka, "System design of 30 bus multi-area smart grid model," in Proc. the Environmental Science Society, August, pp. 173-176, 2016.

[23] Ken Nagasaka, "Development and current state of smart grids: A review," Journal of Advanced Computational Intelligence and Intelligent Informatics (JACIII), vol. 21, no. 1, pp. 49-58, 2017.

[24] The HOKKAIDO Electric Company (HEPCO) Homepage. [Online]. Available: www.hepco.co.jp/info/2014/1189511_1635.html

[25] Organization for Cross-regional Coordination of Transmission Operators (OCCTO) report, "Overview of electric power supply and demand and regional interconnection lines," 2016.

[26] TOHOKU Electric Power Company Report, "Inter-zone, other electric power company and sales electricity purchased fee," 2015. 


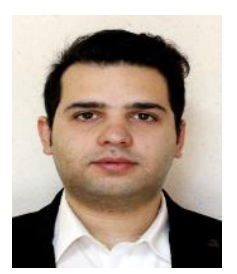

Amin Mohammadirad received his B.S and M.S degree in electrical electronics from Kokushikan University in 2010 and 2012 respectively. Since 2013 , he is working toward his Ph.D. degree in the Department of Electronic and Information of Tokyo University of Agriculture and Technology, Tokyo, Japan. His interest research is on renewable energies, particularly on mega-solar field.

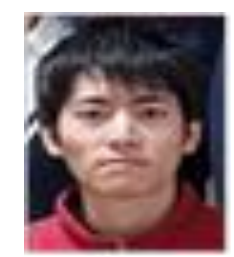

Sho Kainose received his B.S and M.S degree from the Department of Electric and Electronics of Tokyo University of Agriculture and Technology in 2016. His interest research is on renewable energy.

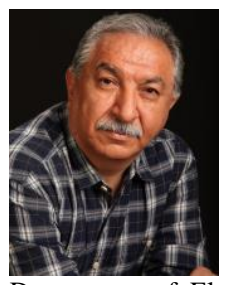

Ken Nagasaka obtained his Ph.D. in electrical engineering from Tokyo Metropolitan University (1990). He became a chief researcher at CSD Company, Tokyo (1990-1991). He became a visiting professor at University of Manitoba, Winnipeg, Canada (1991-1994). He worked as a scientist at Central Research Institute of Electric Power Industry, Tokyo (1994-1998). He became an associate professor at the Department of Electrical Engineering of Tokyo Metropolitan University (1995-1998). Since 1998 he taught and researched at the Graduate School of Engineering, Tokyo University of Agriculture and Technology. Currently, he is a Professor of Tokyo University of Agriculture and Technology. Prof. Nagasaka has published more than 600 papers in the area of power systems and renewable energies. 